\title{
Influence of Electro-oxidation Pretreatment on Anaerobic Digestion Bioprocess
}

\author{
Sonia Khoufi, Emna Feki, Sami Sayadi \\ Laboratoire des Bioprocédés Environnementaux, Laboratoire Mixte Internationale Ecosys MED, \\ Centre de Biotechnologie de Sfax, BP 1177, 3018 Sfax, Tunisia
}

\begin{abstract}
The integration of electro-oxidation (EO) pretreatment for promoting anaerobic digestion of olive mill wastewater $(O M W)$ and waste activated sludge (WAS) was assessed. Results indicated that the application of $E O$ on OMW has permitted high removal efficiencies of chemical oxygen demand (COD) (65\%) and monophenolic compounds (95\%) which resulted in improving the performance of the anaerobic digestion. A continuous lab-scale methanogenic reactor was operated at a loading rate of $10 \mathrm{~g} C O D / L /$ day without any apparent toxicity. However in the case of WAS, EO has improved the disintegration and COD solubilisation of organic matter (28\%). Significant increase in biogas yield (up to 78\%) was observed in the EO pretreated sample compared to raw sludge. These results will open new doors for anaerobic digestion process. Moreover, EO is less expensive, and convenient to use, providing a cost-efficient alternative pretreatment for the improvement of energy recovery.
\end{abstract}

Keywords: Electro-oxidation, olive mill wastewater, waste activated sludge, anaerobic digestion, biogas yield

\section{Introduction}

Anaerobic digestion is a series of biological processes in which microorganisms break down biodegradable material in the absence of oxygen. The process is widely used as a renewable energy source because it produces a methane and carbon dioxide rich biogas suitable for energy production, helping to replace fossil fuels. The nutrient-rich digestate which is also produced can be used as fertilizer. Anaerobic wastewater purification processes have been increasingly used in the last few decades. These processes are important because they have positive effects: removal of higher organic loading, low sludge production, high pathogen removal, methane gas production and low energy consumption [1].

A range of anaerobic digestion technologies are converting livestock manure, municipal wastewater solids, food waste, high strength industrial wastewater and residuals, fats, oils and grease, and various other organic waste streams into biogas. Is was stated that high rate anaerobic systems represent low cost and sustainable technology for industrial wastewaters treatment, because of its low construction, operation and maintenance cost, small land requirements, low excess sludge production and production of biogas. Nevertheless, anaerobic sludge digesters from time to time suffer from a series of operating problems including: (i) Sour digestion syndrome; caused by acid build-up with simultaneous slowing or cessation of gas production, (ii) Grease blankets; caused by the build-up of insolubles on the surface of the digester and (iii) Nutrient imbalance; caused by the lack of certain key micronutrients [1].

Various process methods, e.g., mechanical, chemical, thermal and biological oxidation, have been integrated and reported to enhance the anaerobic digestion [2], while the addition of chemicals and the introduction of heat always resulted in substantial energy input [3]. Within these various technologies aiming to enhance anaerobic digestion, advanced oxidation processes (AOP) are quite effective and economical [4]. AOPs are considered clean technologies for the treatment of polluted waters that apply the concept of producing hydroxyl radicals (HO•). The efficiency of AOPs is based on the generation of these highly reactive radicals that are unselective and powerful oxidizing species $(\mathrm{E} 0=2.80 \mathrm{~V})$. The integration of different AOPs in a sequence of complementary processes is also a common approach to achieve a biodegradable effluent that can be further treated by a cheaper and conventional biological process, reducing the residence time and reagent consumption in comparison with AOPs alone [5]. Some of the most typical AOPs are the Fenton process, ozonation, catalytic wet peroxide oxidation. Regarding the methodology to generate hydroxyl radicals, AOPs can be divided into chemical, electro-chemical, sono-chemical and photochemical processes [5]. 
A number of comprehensive reviews of published oxidation and AOPs studies are conducted on different types of wastewaters. High operational costs have always been the major problem in all AOPs. Therefore, several studies have focused on coupling AOPs with other treatment units, such as anaerobic digesters [6, 7]. Solar titanium dioxide-photocatalysis removed $62 \%$ of COD from the primary anaerobic treatment, resulting in 95\% of global COD removal in dairy wastewater [8]. Almost complete COD removal (99.3\%) was obtained when Fenton's oxidation ( $400 \mathrm{mg} / \mathrm{L} \mathrm{Fe} 2^{+}$and $200 \mathrm{mg} \mathrm{H}_{2} \mathrm{O}_{2} / \mathrm{L}$ ) was coupled to a UASB reactor to treat raw poultry manure wastewater [9].

A combination of electrochemical and Fenton process, namely electro-Fenton method was developed for the improved oxidation of organic compounds [5] and commonly applied for the removal of biorefractory contaminants in the wastewaters [3]. This reaction is among the most eco-friendly electrochemical AOPs and basically consists of an electrically assisted Fenton process. Its oxidation mechanism will generate hydroxyl radicals in the acidic condition by the catalytic decomposition of hydrogen peroxide $\left(\mathrm{H}_{2} \mathrm{O}_{2}\right)$. This $\mathrm{Fe}^{2+} / \mathrm{H}_{2} \mathrm{O}_{2}$ system, often referred to as Fenton's reagent, has dual functions of $\mathrm{OH}^{\cdot}$ radical peroxidation as well as ferrous/ferric coagulation [10]. The Fenton reagents can be added to the reactor and the anode material is an inert electrode or, alternatively, only $\mathrm{H}_{2} \mathrm{O}_{2}$ is added and $\mathrm{Fe}^{2+}$ is provided from sacrificial cast iron anodes [11].

Although, the electro-oxidation process (EO) is known to be effective in the oxidation of pollutants and is widely utilized for the treatment of hazardous wastewaters, no studies have been done to compare its effect on the treatment of olive mill wastewater (OMW) and waste activated sludge (WAS). Therefore, the main objective of this study was to investigate the effect of this EO method on physicochemical characteristics and the anaerobic biodegradability of OMW and WAS. The effectiveness of this pretreatment on the anaerobic digestion will be studied in semi-continuous mode.

\section{Material and Methods}

\subsection{Substrates}

Olive mill wastewater and waste activated sludge were locally obtained (Sfax, southern Tunisia). Fresh OMW was obtained from an olive oil continuous processing plant while WAS are thickened secondary sludge obtained from a municipal wastewater treatment plant. Samples are collected in cans and are stored in a cold room $\left(4^{\circ} \mathrm{C}\right)$ so that they keep their initial biological and physicochemical characteristics. The mean physicochemical characteristics of raw OMW and WAS are shown in Table 1.

\subsection{Electro-oxidation pretreatment}

The EO reactor was formed by one pair of anodic and cathodic electrodes (cast iron plates) which were positioned approximately $1.5 \mathrm{~cm}$ apart from each other and were dipped in the effluent. $\mathrm{H}_{2} \mathrm{O}_{2}$ was added to the electrolytic cell before the electrical current was turned on. Current input was supplied by a convergy power supply. For the pretreatment of OMW, $\mathrm{pH}$ of the solution was adjusted to 4 and optimum $\mathrm{H}_{2} \mathrm{O}_{2}$ concentration and current density were found to be $1 \mathrm{~g} / \mathrm{L}$ and $7.5 \mathrm{~A} / \mathrm{dm}^{2}$, respectively. At these conditions, maximum removal of phenolic monomer concentration, COD and color were attained after $4 \mathrm{~h}$ of pretreatment [12]. For this reason, these conditions were chosen as the optimized parameters and were subsequently used for preparing the pretreated OMW for the biomethanization.

For the EO pretreatment of WAS, experiments were carried out in the same electrolytic process as for pretreatment tests of OMW. However, the objective of WAS pretreatment was to optimize the EO process for maximum solubilization of organic matter and not to decrease COD as investigated for the OMW pretreatment. According to previous study, a current density of $2.5 \mathrm{~A} / \mathrm{dm}^{2}$, a dose of $1.8 \mathrm{~g} / \mathrm{L} \mathrm{H}_{2} \mathrm{O}_{2}$, an initial pH of 3.0 and a treatment time of 1 hour are the best conditions for maximum solubilization of sludge by EO.

\subsection{Anaerobic digestion experiments}

An anaerobic filter (AF) and a continuously stirred tank reactor (CSTR) were respectively used for mesophilic anaerobic digestion of pretreated OMW and WAS by EO. AF was made of a glass column having a working volume of 31 which was packed with polyurethane foam cubes (Filtren T45, from Recticel, Wetteren, Belgium) as support and inoculated with an 8-year-old digester operated with pretreated OMW.

The CSTR has a total volume of $2.5 \mathrm{~L}$ and a working volume of $1.5 \mathrm{~L}$. The stirring intensity and frequency were $60 \mathrm{rpm}$ and 24 times per day ( 2 min for each mixing), respectively. The system was operated in a semi- 
continuous mode by loading with the prepared feedstocks once a day. At each OLR, the $\mathrm{pH}$, biogas production, COD, TS, and VS were determined. When biogas production was steady at an operating OLR, which occurred after about 10-20 days of continuous digestion, next higher level of OLR was operated. At the steady stage, all parameters were measured every day. The whole system ran for more than 140 days.

The gas flow rates of digesters were measured by liquid displacement. Gas samples were taken with a syringe from the tank of biogas. $\mathrm{CH}_{4}, \mathrm{CO}_{2}$ and $\mathrm{N}_{2}$ were measured using a gas chromatograph GC11 (Delsi instruments) equipped with a Haye SepQ 60/80 (SUPELCO) column (maintained at 60 1C), a thermal conductivity detector (current intensity of $160 \mathrm{~mA}$ ) and a servotrace integrator (SEFRAM). Helium was used as a carrier gas at a pressure of 1.3 bar.

\subsection{Analytical analysis}

The characterization of treated and untreated effluent included determination of the following parameters: $\mathrm{pH}$, soluble chemical oxygen demand (soluble COD), total chemical oxygen demand (total COD), Biological oxygen demand $\left(\mathrm{BOD}_{5}\right)$, total (TS) and volatile (VS) solids, total (TSS) and volatile (VSS) suspended solids, total kjeldahl nitrogen (TKN), ammonium nitrogen and ortho-diphenols.

Samples were centrifuged for $20 \mathrm{~min}$ at $4000 \mathrm{t} / \mathrm{min}$ and diluted appropriately before each COD determination. As the presence of residual $\mathrm{H}_{2} \mathrm{O}_{2}$ introduces a positive error in COD determination, in electrolysis experiments with $\mathrm{H}_{2} \mathrm{O}_{2}$, the $\mathrm{pH}$ of the samples was raised to above 10 with $\mathrm{NaOH} 6 \mathrm{~N}$ prior to analysis [13]. The value of COD was estimated using the method described by Knechtel [14].

The COD solubilization of WAS represented the transfer of organic matter from the particulate fraction of the sludge to the soluble fraction. COD solubilization was calculated according to this formula:

$$
\text { COD solubilization }(\%)=\frac{\text { SCODafter }- \text { SCOD0 }}{\text { TCOD }- \text { SCOD } 0} \times 100
$$

Where $\mathrm{SCOD}_{\text {after }}$ is the soluble COD after pretreatment, $\mathrm{SCOD}_{0}$ is the soluble COD before pretreatment, and TCOD is the total COD before pretreatment of sludge. This value represented the disintegration degree of WAS that could directly tell the portion of particle substances solubilized by pretreatment [15].

$\mathrm{BOD}_{5}$ was determined by the manometric method with a respirometer [BSB-ControllerModel $620 \mathrm{~T}$ (WTW)]. TS and TSS were determined by weighing samples before and after drying overnight at $105^{\circ} \mathrm{C}$. VS and VSS were analysed, by loss on ignition at $600^{\circ} \mathrm{C}$ for $2 \mathrm{~h}$. The Total Kjeldahl nitrogen content (TKN) and the ammoniacal nitrogen $\left(\mathrm{N}-\mathrm{NH}_{4}{ }^{+}\right)$were analysed as Kjeldahl-N method.

Concentration of ortho-diphenols was determined by the colorimetric reaction with Folin-Ciocalteau reagent. An aliquot of the OMW aqueous methanol extract was mixed with $2 \mathrm{ml}$ of Folin-Ciocalteau reagent (Fluka, Switzerland). A sodium hydroxide solution $(6 \% \mathrm{v} / \mathrm{v})$ was added, and the mixture was shaken. The blue color formed was measured at $727 \mathrm{~nm}$. The ortho-diphenol concentration of OMW samples, as determined by the Folin-Ciocalteau method [16], was reported as caffeic acid equivalents by reference to a standard curve.

\section{Results and Discussion}

\subsection{Effect of EO on OMW and WAS properties}

Table I shows the characteristics of OMW before and after EO treatment. TSS in crude OMW is an unsettlable suspended matter, which presents a major difficulty in the treatment and handling of OMW. During EO treatment, $\mathrm{pH}$ increased from 4 to 7.6, which may be attributed to the smaller production of $\mathrm{H}^{+}$than $\mathrm{OH}^{-}$[17] and the reduction in phenol concentration. Indeed, phenols are acids in liquids, and their removal from a solution reduces its acidity. The $\mathrm{pH}$ value of EO-treated OMW can be considered favorable for anaerobic bio-treatment.

After EO, the COD of raw OMW drops to approximately $68 \%$ of the initial value. This result points out the ability of the electrolysis process to eliminate soluble compounds present in OMW. It appears that a significant proportion of the non-biodegradable matter present in OMW was removed. Degradation and mineralisation of phenolic compounds can occur during Fenton reaction. Kavitha and Palanivelu [18] reported that in Fenton process, biodegradable aliphatic compounds such as acetic acid and oxalic acid were identified as the major products during the degradation of synthetic phenol. However, the concentration of ortho-diphenols, monitored 
by Folin-Ciocalteau method, was significantly reduced during EO process. Removal efficiency was about $65.8 \%$ for total polyphenols and $74.5 \%$ for ortho-diphenols. Crude OMW was highly colored due to its high content of polyaromatic compounds. In the beginning of the electrolysis treatment, the color intensity of the effluent increased (data not shown) as a result of phenolic compounds polymerization. However, color intensity decreased to $78 \%$ at the end of treatment.

During EO treatment, a part of the solute and particle matter present in OMW turned out to be a suspended solid that could reach $40 \mathrm{~g} / \mathrm{L}$ at the end of the electrolysis reaction. These TSS were rapidly eliminated by simple sedimentation. After decantation, the obtained effluent has low quantity of TSS $(2 \mathrm{~g} / \mathrm{L})$ in comparison with the decanted raw OMW (12 g/L). The formation of suspended particles was caused presumably by electrocoagulation process. The polymers were precipitated with iron which was continuously dissolved into the wastewater from the cast iron anodes, as governed by the Faraday's law. This result confirms the hypothesis that the EO reaction would have a strong ability to eliminate polyphenols from OMW. The $\mathrm{pH}, \mathrm{COD}$, coloration, ortho-diphenols and TSS removal were consistently very good. Indeed, the effluent quality of the pretreated OMW by EO process was rather excellent (Table I). It could be directly fed as influent to anaerobic reactor.

\begin{tabular}{lcccc} 
TABLE I: Physicochemical characteristics of raw and pretreated on \\
\hline \hline Parameters & Raw & Pretreated & Raw & Pretreated \\
& OMW & OMW & WAS & WAS \\
\hline pH & 5.4 & 7.6 & 7.0 & 7.6 \\
Total COD g/l & 132.5 & 53.8 & 18.3 & 17.5 \\
Soluble COD g/l & 112.5 & 36.0 & 1.9 & 4.9 \\
BOD $_{5}$ g/L & 19.2 & 15.5 & 3.2 & 4.5 \\
TSS g/l & 59.0 & 2.7 & 27.0 & 24.3 \\
VSS g/l & 55.2 & 2.3 & 17.94 & 22.0 \\
TS g/l & 122.0 & 39.0 & 34.2 & 30.5 \\
VS g/l & 109.0 & 21.0 & 21.5 & 27.1 \\
Ortho-diphenols mg/l & 6025.5 & 1536.7 & - & - \\
\hline \hline
\end{tabular}

The same EO process was investigated for the pretreatment of WAS. However, for this kind of waste, the EO method was suggested to improve the solubilization/disintegration of WAS. WAS is composed of diverse microorganisms, organic and inorganic compounds agglomerated together in a polymeric network formed by extracellular polymeric substances (EPS), including proteins, carbohydrates, lipids and volatile fatty acids [19]. These EPS strongly influence the hydrolysis step of WAS during anaerobic digestion. In order to overcome this rate restricting step and to enhance the digesting capability, EO method was suggested for the disintegration of WAS. Therefore, various parameters involved in EO reaction, especially the $\mathrm{pH}$, current density, the concentration of $\mathrm{H}_{2} \mathrm{O}_{2}$ and the processing time were studied (data not shown) in order to maximize the organic matter solubilization. Results demonstrated that under optimal operational parameters EO pretreatment has improved the COD solubilization. A significant increase of soluble COD about $18 \%$ compared to raw WAS was registered. Furthermore, a reduction of TSS by the EO reaction was found. As described by He and Wei [20], the solubilization of sludge was carried out in two steps. In the first step, flocs were dissociated to single microorganisms which were killed and oxidized to dissolve organic substances in the second step. Once in solution, $\mathrm{H}_{2} \mathrm{O}_{2}$ can react with the $\mathrm{Fe}^{2+}$ ions thus initiating the so called Fenton's radical reaction chain which leads to the production of the reactive oxygen species $\mathrm{OH}^{\cdot}$ [21]. The latter one, given its high reactivity, is capable to attack and effectively degrade the organic compounds constituting EPS and the cell wall, thus leading to its rupture and the subsequent release of intracellular content in solution. An increase of $\mathrm{pH}$ was observed, the final $\mathrm{pH}$ reached to 7.6. This result is quite meaningful in the application of EF as a pretreatment for WAS before anaerobic digestion, because it can be directly used as influent without further $\mathrm{pH}$ adjustment of wastewater.

\subsection{Anaerobic digestion}

\subsubsection{Pretreated OMW}

The digester was loaded with undiluted pretreated OMW at a starting loading rate of $2 \mathrm{~g} \mathrm{COD} / \mathrm{L} / \mathrm{d}$. The reactor was operated at influent OMW concentration of $35.5 \mathrm{~g} \mathrm{COD} / \mathrm{L}$ (mean value). The hydraulic retention 
time (HRT) varied between 17.7 and 3.5 days. In general, the percentage of COD removal decreased with increased loading rate during the fermentation of OMW in the reactor (Table II). The percentage of COD removal decreased from $88.8 \%$ to $68 \%$ when the organic loading rate increased from 2 to $10 \mathrm{~g} \mathrm{COD/L/d} \mathrm{(Table}$ II). At the higher loading rates $(9-10 \mathrm{~g} \mathrm{COD} / \mathrm{L} / \mathrm{d})$, the yields obtained were approximately $0.3 \mathrm{~L} \mathrm{CH}_{4} / \mathrm{g} \mathrm{COD}$ introduced. The volume of biogas reached $12 \mathrm{~L} / \mathrm{d}$ (4-fold of the volume of the digester). The higher values of yields (0.32-0.34 $\mathrm{L} \mathrm{CH}_{4} / \mathrm{g}$ COD introduced) were obtained for loading rates lower than $8 \mathrm{~g} \mathrm{COD/L/d.} \mathrm{In} \mathrm{addition,}$ the methane yield increased with the increase of the loading rate up to the theoretical steady yield value, reported to be around $0.35 \mathrm{~L} \mathrm{CH}_{4} / \mathrm{g}$ COD introduced. This observation can be considered a solid proof for the ability of the anaerobic biomass to degrade most organic matter present in the EO-pretreated OMW. Besides, it may confirm the gradual increase of the methanogenic activity. The biomethanisation process was found to be stable during 3 months of operation. No toxicity phenomenon was observed. VFAs have long been recognised as the most important intermediates in the anaerobic process and were proposed as a control parameter [22]. Therefore, VFA and $\mathrm{pH}$ were analysed in knowing that untreated OMW causes inhibition of methanisation at a loading rate of 2-4 g COD/L/d [12], it can be concluded that EO pretreatment of OMW resulted in decreasing the toxic effect of this wastewater on anaerobic digestion. Moreover, this experiment was stopped at a loading rate of $10 \mathrm{~g}$ $\mathrm{COD} / \mathrm{L} / \mathrm{d}$ while the biological process did not show any apparent toxicity. These results also suggest that anaerobic digestion can be a practical alternative for the treatment of OMW.

TABLE II: Average methane yield, methane content and COD removal during anaerobic digestion of pretreated OMW under different loading rate

\begin{tabular}{lccc}
\hline \hline $\begin{array}{l}\text { OLR } \\
\text { g COD/l/day) }\end{array}$ & $\begin{array}{c}\text { Methane } \\
\text { Yield } \\
(1 / g \text { COD })\end{array}$ & $\begin{array}{c}\text { Methane } \\
\text { content } \\
(\%)\end{array}$ & $\begin{array}{c}\text { COD } \\
\text { Removal } \\
(\%)\end{array}$ \\
\hline 2 & 0.3 & 68 & 88 \\
4 & 0.22 & 67 & 80 \\
5 & 0.25 & 65 & 75 \\
7 & 0.32 & 68 & 70 \\
8 & 0.35 & 69 & 67 \\
10 & 0.31 & 71 & 68 \\
\hline \hline
\end{tabular}

\subsubsection{Pretreated WAS}

To investigate effects of EO on the anaerobic sludge digestion, experiment was conducted in a CSTR and the fermentation was lasted for 80 days. The applied organic loading rate, biogas production, biogas yield and $\mathrm{pH}$ of influent and effluent vs. fermentation time are recorded in Fig. 1. From this figure, the biogas production increased with the increase of OLR. It reached $1.4 \mathrm{~L} / \mathrm{d}$ at an OLR of $4 \mathrm{~g} \mathrm{COD} / \mathrm{L}$ reactor/d. At day 70, a decrease of biogas production was registered caused by a technical problem in the agitation system. An increase of biogas yield was also shown. It fluctuated between 0.1 and $0.25 \mathrm{~L} / \mathrm{g}$ COD introduce at OLR of $0.75-2 \mathrm{~g}$ COD/L reactor/day. With the increase of time fermentation, an improvement of biogas yield was observed. It reached to an average value of $0.45 \mathrm{~L} / \mathrm{g}$ COD introduced at an OLR of $4 \mathrm{~g} \mathrm{COD} / \mathrm{L}$ reactor/d. However, a biogas yield about $0.05 \mathrm{~L} / \mathrm{g}$ COD was obtained by digesting raw WAS (data not shown). This demonstrate the positive effect of EO the anaerobic digestion of WAS. 

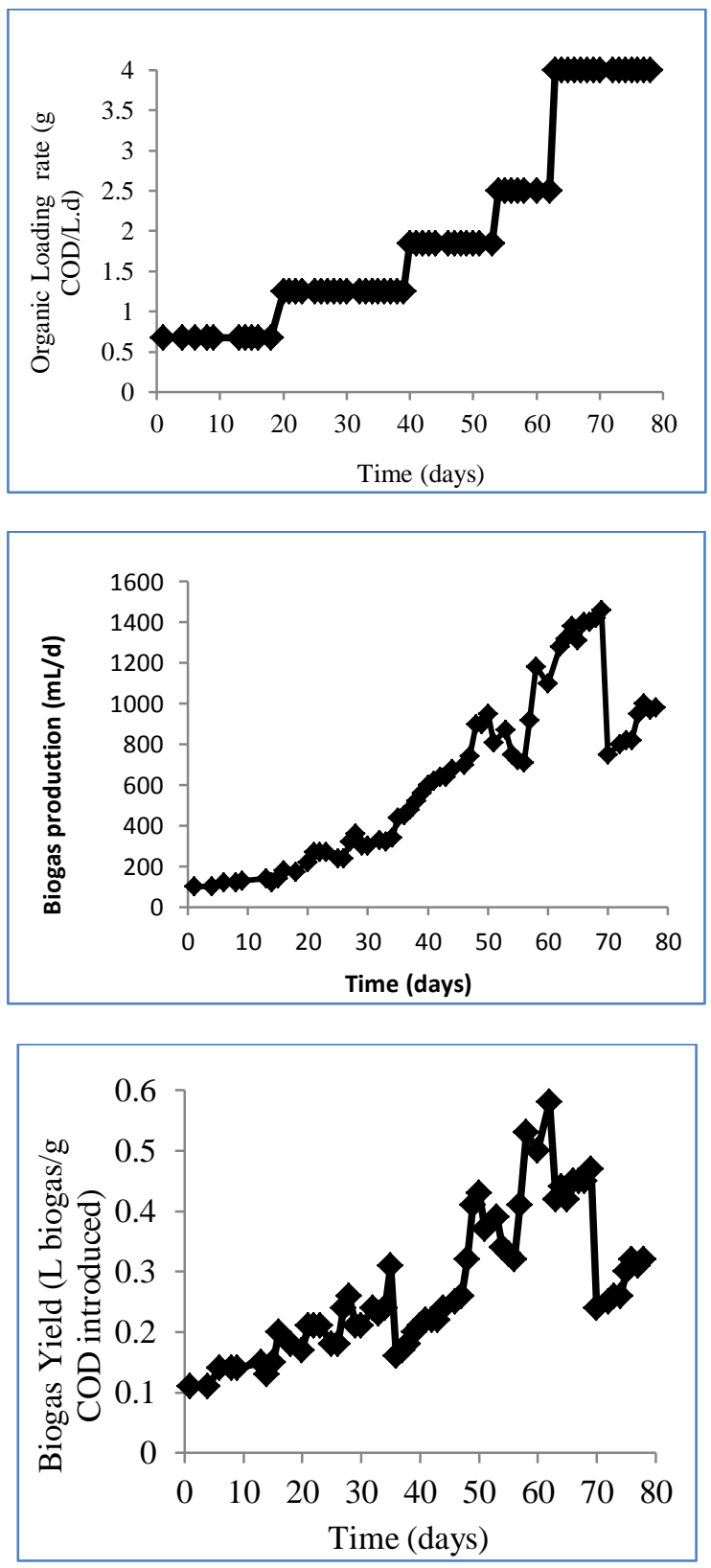

Fig. 1: Evolution of organic loading rate, biogas production and biogas yield during anaerobic digestion of pretreated WAS.

The biomethanisation process was found to be stable during the fermentation of pretreated WAS. The biogas production was proportional to the loading rate. However, biogas production cannot be used to detect inhibition of anaerobic digester. Thus, it does not reflect the state of imbalance in the reactor. Anaerobic digestion is a complex process consisting of a series of microbial transformation of organic materials to methane and VFA such as acetate, propionate, butyrate, iso-butyrate, valerate and iso-valerate. Changes in VFA concentration can be in response to variation in temperature, organic loading rates or the presence of toxicants. The dynamics of VFA production and $\mathrm{pH}$ measurements in the reactor were determined. The evolution of $\mathrm{pH}$ showed stability and optimal values (pH: 7.3-7.6) (Fig. 2). The VFA concentrations were low even at the organic loading rate (data not shown). It is concluded from this anaerobic study that the pretreatment of WAS by EO is beneficial and constitutes an interesting solution to overcome the low biodegradability of WAS. This resulted to better biogas yield and a highly buffered system. This enhancement was due to the increase in solubilization of WAS by the pretreatment. 


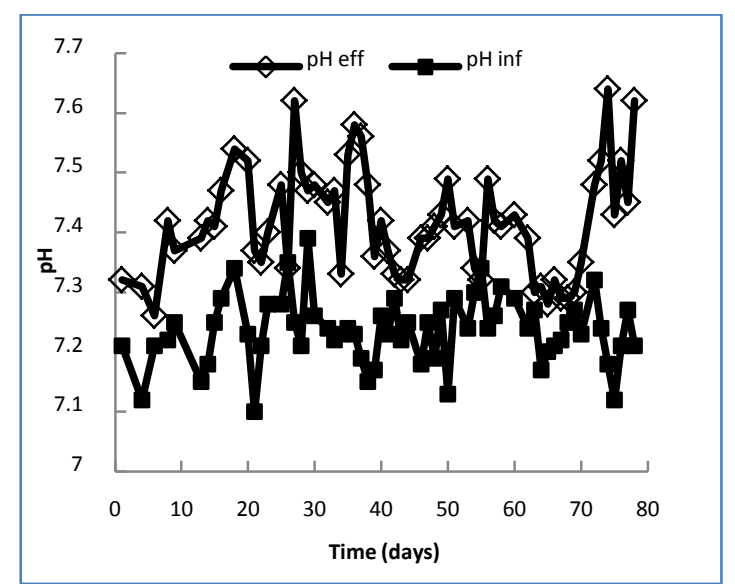

Fig. 2: Evolution of $\mathrm{pH}$ of influent and effluent during anaerobic digestion of pretreated WAS

Erden and Filibeli [6] studied the effect of Fenton pretreatment on anaerobic sludge bioprocessing and compared between single stage anaerobic digestion under thermophilic condition and two-stage anaerobic digestion (mesophilic then thermophilic digestion). Results showed that Fenton pretreatment provided 1.4 and 1.2 times higher methane production in single stage and two-stage digestion, respectively, than the total methane productions in control reactors. In batch mesophilic anaerobic digestion of a mixture of iron-rich sludge collected from Fenton treatment of molasses wastewater and thickened sewage sludge from a municipal wastewater treatment plant, the methane content in the gas from the mixture was significantly higher than that from thickened sewage sludge only [23]. The presence of iron seems enhance the activity of methanogens. Besides, it could increase the methane production from the enhancement of acetate generation which is a suitable substrate for methanogenesis. Thus, the Fenton reaction pre-treatment both raised the methane production and also improved the biodegradation of sludge.

\section{Conclusion}

From the date reported above, EO is an effective technology for improving the physicochemical characteristics and the anaerobic digestion performance of OMW and WAS. The stimulation of anaerobic digestion in the two cases can be explained by: (i) the improvement of biodegradability, (ii) the acceleration of biochemical hydrolysis reactions prior to anaerobic digestion and (iii) the increase of methanogens activity in the presence of iron. Future work should focus on the determination of the toxicity, kinetics models and reactor design. Besides, comprehensive economical analysis (including energy, chemical and maintenance costs, and methane production) should be further investigated prior to practical implementation.

\section{Acknowledgements}

This research was supported by the Contrat Programme of "Ministère de l'Enseignement Supérieur et de la Recherche Scientifique", Tunisie and by the International Foundation for Science, Research Grant Agreement No W/5412-1.

\section{References}

[1] C. Maoa, Y. Feng, X. Wang and G. Ren, "Review on research achievements of biogas from anaerobic digestion," Renewable and Sustainable Energy Reviews, vol. 45, pp. 540-555, 2015. http://dx.doi.org/10.1016/j.rser.2015.02.032

[2] J. Kim, C. Park, T.H. Kim, M. Lee, S. Kim, SW. Kim and J. Leej, "Effects of various pretreatments for enhanced anaerobic digestion with waste activated sludge," J Biosci Bioeng, vol. 95, pp. 271-275, 2003. http://dx.doi.org/10.1016/S1389-1723(03)80028-2

[3] RR. Ana, CN. Olga, FRP. Manuel and MTS. Adrián, "An overview on the advanced oxidation processes applied for the treatment of water pollutants defined in the recently launched Directive 2013/39/EU," Envi Inter, vol. 75, pp. 33$51,2015$.

http://dx.doi.org/10.1016/j.envint.2014.10.027 
[4] M. Tokumura, H. Katoh, T. Katoh, HT. Znad and Y. Kawase, "Solubilization of excess sludge in activated sludge process using the solar photo-Fenton reaction," J Hard Mater, vol. 162, pp. 1, 2009.

http://dx.doi.org/10.1016/j.jhazmat.2008.06.026

[5] A. Babuponnusamia and K. Muthukumar, "Advanced oxidation of phenol: A comparison between Fenton, electroFenton, sono-electro-Fenton and photo-electro-Fenton processes," Chem Eng J, vol. 183, pp. 390-1396, 2012. http://dx.doi.org/10.1016/j.cej.2011.12.010

[6] G. Erden and A. Filibeli, "Improving anaerobic biodegradability of biological sludges by Fenton pre-treatment: Effects on single stage and two-stage anaerobic digestion," Desalination, vol. 25, pp. 58-63, 2010. http://dx.doi.org/10.1016/j.desal.2009.09.144

[7] S. Kavitha, S Adish Kumar, S Kaliappan, IT Yeom and J. Rajesh Banu, "Improving the amenability of municipal waste activated sludge for biological pretreatment by phase-separated sludge disintegration method" Biores Technol, vol. 169, pp. 700-706, 2014.

http://dx.doi.org/10.1016/j.biortech.2014.07.065

[8] J. Rajesh Banu, S. Anandan, S. Kaliappan and Ick-Tae Yeom, "Treatment of dairy wastewater using anaerobic and solar photocatalytic methods," Solar Energy, vol. 82 (9), pp. 812-819, 2008. http://dx.doi.org/10.1016/j.solener.2008.02.015

[9] K. Yelilmezsoy and S. Sakar, "Improvement of COD and color removal from UASB treated poultry manure wastewater using Fenton's oxidation," J Hard Mat, vol. 151, pp. 547-558, 2008.

http://dx.doi.org/10.1016/j.jhazmat.2007.06.013

[10] D Güçlü, S. Şahinkaya and N. Şirin, "Post-treatment of coking industry wastewater by the electro-Fenton process," Water Environ Res, vol. 85, pp. 391-396, 2013. http://dx.doi.org/10.2175/106143013X13596524516662

[11] PV. Nidheesh and R. Gandhimathi, "Trends in electro-Fenton process for water and wastewater treatment: an overview," Desalination, vol. 299, pp. 1-15, 2012. http://dx.doi.org/10.1016/j.desal.2012.05.011

[12] S. Khoufi, F. Aloui and S. Sayadi, "Treatment of olive oil mill wastewater by combined process electro-Fenton reaction and anaerobic digestion," Water Res, vol. 40, pp. 2007-2016, 2006. http://dx.doi.org/10.1016/j.watres.2006.03.023

[13] Y.W. Kang, M.J. Cho, K.H. Hwang, "Correlation of hydrogen peroxide interference on standard chemical oxygen demand test," Water Res, vol. 33, 1247-1251, 1999.

http://dx.doi.org/10.1016/S0043-1354(98)00315-7

[14] JR. Knechtel, "A more economical method for the determination of chemical oxygen demand," Water Pollut Control, vol. 116, pp. 25-27, 1978.

[15] H. Li, C. Li, W. Liu and S. Zou, "Optimized alkaline pretreatment of sludge before anaerobic digestion," Biores Technol, vol. 123, pp. 189-194, 2012. http://dx.doi.org/10.1016/j.biortech.2012.08.017

[16] O. Folin and U. Ciocalteau, "On tyrosine and tryptofan determinations protein," J Biol Chem, vol. 73, pp. 627-650, 1927.

[17] C.J. Israilides, A.G. Vlyssides, V.N. Mourafeti, G. Karvouni, "Olive oil wastewater treatment with the use of an electrolysis system," Biores Technol, vol. 61 (2), pp. 163-170, 1997.

http://dx.doi.org/10.1016/S0960-8524(97)00023-0

[18] V. Kavitha and K. Palanivelu, "The role of ferrous ion in Fenton and photo-Fenton process for the degradation of phenol," Chemosphere, vol. 55, pp. 1235-1243, 2004. http://dx.doi.org/10.1016/j.chemosphere.2003.12.022

[19] C. Eskicioglu, KJ. Kennedy and RL. Droste, "Characterization of soluble organic matter of waste activated sludge before and after thermal pretreatment," Water Res, vol. 40, pp. 3725-3736, 2006. http://dx.doi.org/10.1016/j.watres.2006.08.017

[20] MH. He and CH. Wei, "Performance of membrane bioreactor (MBR) system with sludge Fenton oxidation process for minimization of excess sludge production," J Hard Mater, vo. 176, pp. 597-601, 2010.

http://dx.doi.org/10.1016/j.jhazmat.2009.11.071 
[21] Q. Yu, HY. Lei, Z. Li, HL. Li, K. Chen, XH. Zhang and RL. Liang, "Physical and chemical properties of wasteactivated sludge after microwave treatment," Water Res, vol. 44, pp. 2841-2849, 2010. http://dx.doi.org/10.1016/j.watres.2009.11.057

[22] T. Mechichi and S. Sayadi, "Evaluating process imbalance of anaerobic digestion of olive mill wastewaters," Process Biochem, vol. 40 (1), pp. 139-145, 2005. http://dx.doi.org/10.1016/j.procbio.2003.11.050

[23] H. Lee, M. Shoda, "Stimulation of anaerobic digestion of thickened sewage sludge by iron-rich sludge produced by the fenton method," J Biosci Bioeng, vol. 106, pp. 107-110, 2008.

http://dx.doi.org/10.1263/jbb.106.107 